\title{
Review: after myocardial infarction, depression and poor prognosis are associated
}

van Melle JP, De Jonge P, Spijkerman TA, et al. Prognostic association of depression following myocardial infarction with mortality and cardiovascular events: A meta-analysis. Psychosom Med 2004;66:814-22.

Does depression after a myocardial infarction affect cardiovascular prognosis and survival?

\section{METHODS}

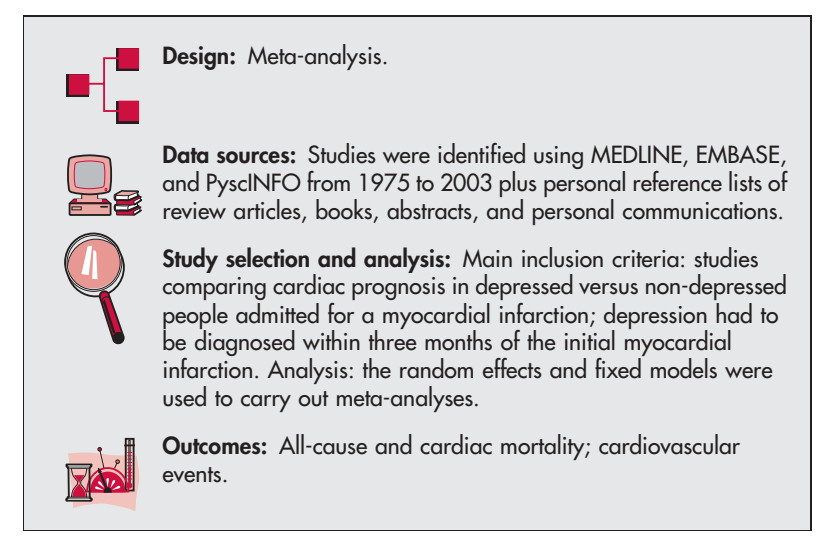

\section{MAIN RESULTS}

Twenty two studies met inclusion criteria $(n=6367)$. All-cause and cardiac mortality were increased in depressed versus non-depressed people (all cause mortality: 96/952 (10.1\%) with depression $v 116 /$ $2130(5.5 \%)$ with no depression, $\mathrm{n}=3082$, OR $2.38,95 \%$ CI 1.76 to 3.22, $\mathrm{p}<0.00001$; cardiac mortality: 62/1091 (5.8\%) with depression $v$ $57 / 2252(2.6 \%)$ with no depression, $\mathrm{n}=3343$, OR $2.59,95 \% \mathrm{CI} 1.77$ to $3.77, \mathrm{p}<0.00001)$. Cardiovascular events were increased in depressed versus non-depressed people (cardiovascular events: 325/1078 $(30.2 \%)$ with depression $v 449 / 2323$ (19.4\%), $\mathrm{n}=3401$, OR 1.95 , 95\% CI 1.33 to 2.85 ).

\section{CONCLUSIONS}

All-cause and cardiac mortality plus cardiovascular events are more common in depressed versus non-depressed people after a myocardial infarction.

\section{NOTES}

The authors note there is some evidence for selective reporting of cardiovascular mortality results in the medical literature. The direction of causation is unclear: depression may worsen prognosis or result from more severe cardiac disease.
For correspondence: Joost $\mathrm{P}$ van Melle, $\mathrm{MD}$, Research Fellow, Cardiology, Department of Cardiology, Thorax Center, University Hospital Groningen, PO Box 30.001. 9700 RB, the Netherlands; i.p.van.melle@thorax.azg.nl Sources of funding: not stated.

\section{Commentary}

T he precise nature of the relation between depression following myocardial infarction (MI) and prognosis has been the subject of much recent debate ${ }^{1-3}$ and the relevant prospective observational studies have now been meta-analysed by van Melle et al. The pooled odds ratios-2.38, 2.59, and 1.95-for all-cause mortality, cardiac mortality, and cardiovascular events respectively, indicated a significantly poorer prognosis for those who were depressed following MI. The means of assessing depression (depressive symptomatology or major depressive disorder) and the length of follow up (0-6 months and >6 months) did not influence the strength of the association between depression and outcome. However, as the authors readily concede, these conclusions are based on pooling bivariate analyses, not multivariate analyses. As has been argued previously, ${ }^{4}$ adjusting for potential confounders, such as disease severity, is necessary to determine whether depression following $\mathrm{Ml}$ is an independent risk factor-that is, causative-in this context. van Melle et al note that where multivariate analyses were performed, the association between depression and outcome was almost invariably attenuated from the bivariate association. It is unfortunate that so few studies present multivariate analyses for consideration and in their absence, we should, as the authors state, "remain careful before making causal inferences".

Whether or not depression following $\mathrm{Ml}$ is an independent risk factor for prognosis is an important public health matter. To date, only one randomised controlled trial in this population has been published; cognitive behaviour therapy, supplemented when necessary with antidepressive medication, was associated with significant reductions in depressive symptomatology, but had no effect on all-cause mortality or recurrent non-fatal Ml. ${ }^{5}$ However, outcomes other than mortality and cardiac morbidity need to be considered. The MIND-IT trial, ${ }^{6}$ in addition to investigating the impact of antidepressant medication on mortality following MI, also considers its impact on quality of life. The findings are due to be published soon. Even if it shows that treating depression affects quality of life in Ml patients, but not mortality or morbidity, this will be an important result. Given the high prevalence and persistence of depression during the first 12 months following $\mathrm{Ml}$, as well as its detrimental impact on participation in cardiac rehabilitation and compliance with medication, reduced quality of life should be a sufficient imperative for treatment. Dr Deirdre A Lane University Department of Medicine, City Hospital, Birmingham, UK Professor Douglas Carroll School of Sport and Exercise Sciences, University of Birmingham, Birmingham, UK

1 Lane D, Carroll D, Lip GYH. Reply to Pickering et al and Carney et al. J Am Coll Cardiol 2004;44:473-4.

2 Pickering TG, Davidson K, Shimbo D. Is depression a risk factor for coronary heart disease? J Am Coll Cardiol 2004;44:472-3.

3 Carney RM, Freedland KE, Jaffe AS, et al. Depression a risk factor for postMI mortality. J Am Coll Cardiol 2004;44:472.

4 Lane D, Carroll D, Lip GYH. Anxiety, depression, and prognosis after myocardial infarction: Is there a causal association? J Am Coll Cardiol 2003;42:1808-10

5 The ENRICHD Investigators. The effects of treating depression and low social support on clinical events after myocardial infarction: the enhancing recovery in coronary heart disease patients (ENRICHD) randomised trial. JAMA 2003;289:3106-16.

6 van den Brink RH, van Melle JP, Honig A, et al. Treatment of depression after myocardial infarction and the effects on cardiac prognosis and quality of life: Rationale and outline of the Myocardial Infarction and DepressionIntervention Trial (MIND-IT). Am Heart J 2002;144:219-25. 